\title{
Qualifikationsnachweis auch ohne Kolloquium möglich
}

- Nach einem Urteil des Landessozialgerichts (LSG) Niedersachsen-Bremen kann eine Kassenärztliche Vereinigung (KV) bei der Genehmigung qualifikationsabhängiger Leistungen nur dann ein Kolloquium fordern, wenn Restzweifel an der Qualifikation des betreffenden Arztes bestehen.

Im konkreten Fall ging es um die ärztliche Qualifikation nach der Ultraschallvereinbarung. Ein Vertragsarzt, der viele Jahre als Krankenhausarzt in leitender Stellung gearbeitet hatte, wollte nach seiner Niederlassung Leistungen der Ultraschalldiagnostik durchführen und abrechnen. Die zuständige KV hatte zwar die Qualifikation des Arztes als eine im Vergleich zur Ultraschallvereinbarung abweichende, aber gleichwertige Befähigung anerkannt, forderte ihn aber dennoch zur Teilnahme an einem Kolloquium auf. Das LSG urteilte nun, dass dies nicht zwingend notwendig ist, da die Genehmigung nur dann von der erfolgreichen Teilnahme an einem Kolloquium abhängig gemacht werden kann, wenn trotz der vorgelegten Bescheinigung und

Dokumentation begründete Zweifel an der fachlichen Befähigung des Arztes bestünden. Dies sei jedoch nur erforderlich, um Restzweifel auszuräumen (LSG NiedersachsenBremen, Urteil vom 17. Oktober 2012, AZ.: K 3 KA 70/11).

Wie weist man die fachliche Befähigung zur Ultraschalldiagnostik nach?

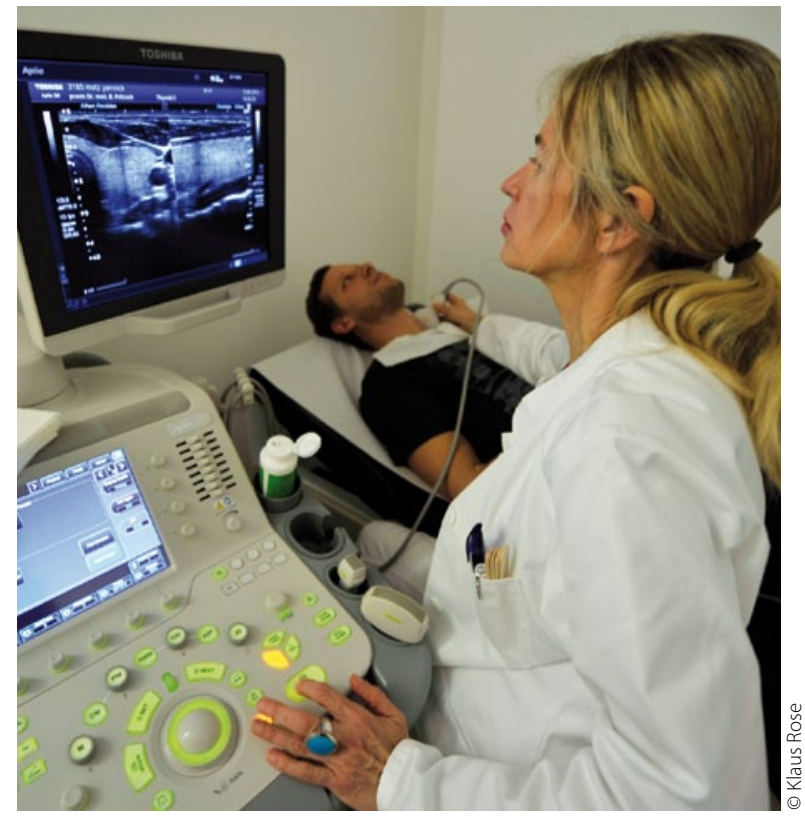

\section{MMW Kommentar}

Die rechtliche Grundlage für diese Entscheidung der Richter ist in der Einschränkung der Berufsausübungsfreiheit nach Art. 12 Abs. 1 Grundgesetz begründet. Danach ist die Verpflichtung zur Durchführung eines Kolloquiums fachlich nur gerechtfertigt, wenn die in der vertrags- ärztlichen Versorgung als notwendig angesehene Versorgungsqualität der Versicherten gesichert werden soll. Ist dies - durch die Vorlage entsprechender Bescheinigungen - gewährleistet, kann auch bei Abweichung von den Richtlinien eine Genehmigung erteilt werden.

\section{Achtung:}

\section{Hier muss der Dummy durch eine Anzeige ersetzt werden !!}

